\title{
Availability, Range and Utilization of Sexual and Reproductive Health (SRH) Services for Adolescents at Kinondoni Municipality, Dar es Salaam-Tanzania
}

\author{
Bupe Khalison Mwandali ${ }^{*}$, Sia Emmanueli Msuya², Adela Abel Mwakanyamale \\ ${ }^{1}$ Department of Maternal and Child Health, Kairuki School of Nursing, Hubert Kairuki Memorial University, Dar es Salaam, Tanzania \\ ${ }^{2}$ Department of Community Medicine, Kilimanjaro Christian Medical University College, Moshi, Tanzania \\ ${ }^{3}$ Department of Medical and Surgical Nursing, Faculty of Nursing, Hubert Kairuki Memorial University, Dar es Salaam, Tanzania \\ Email: `b_khalison@yahoo.co.uk,siaemmanuelimsuya@gmail.com, ademwaka@yahoo.com
}

How to cite this paper: Mwandali, B.K., Msuya, S.E. and Mwakanyamale, A.A. (2020) Availability, Range and Utilization of Sexual and Reproductive Health (SRH) Services for Adolescents at Kinondoni Municipality, Dar es Salaam-Tanzania. Open Journal of Nursing, 10, 286-307.

https://doi.org/10.4236/ojn.2020.103020

Received: February 7, 2020

Accepted: March 24, 2020

Published: March 27, 2020

Copyright $\odot 2020$ by author(s) and Scientific Research Publishing Inc. This work is licensed under the Creative Commons Attribution International License (CC BY 4.0).

http://creativecommons.org/licenses/by/4.0/

(c) $\underset{\mathrm{By}}{\text { (i) Open Access }}$

\begin{abstract}
Background: It is estimated 1.2 billion of world's population are adolescents aged 10 - 19 years; 80\% live in developing countries. Adolescents in developing countries especially Sub-Saharan Africa (SSA) face high burden of sexual and reproductive health problems. Sixteen million girls aged 15 to 19 years give birth every year of which $95 \%$ occur in low- and middle-income countries. Twenty five percent of unsafe abortions are in $15-19$ years in Sub-Saharan Africa. Contraceptive use is low as approximately $10 \%$ of adolescents are current users. These problems can be averted if different ranges of Sexual and Reproductive Health Services for adolescent (SRHSA) are available and utilized by adolescents. In Tanzania, there is limited information addressing the availability, types and utilization pattern of sexual and reproductive health services by adolescents. This study investigates the availability, range and utilization of sexual and reproductive health services for adolescents (ASRHS) at Kinondoni Municipality, Tanzania. Method: A cross-sectional study was carried out in April to May 2013. A checklist was used to collect information on the availability and range of services offered at selected health facilities. In depth interviews conducted with in-charges of Reproductive and Child Health ( $\mathrm{RCH})$ clinics to explore barriers for provision of Sexual and Reproductive Health Services (SRHS) for adolescents. Adolescents were questioned using a questionnaire on utilization of SRHS and perceived barriers. Descriptive statistics were used to summarize quantitative data and content analysis for qualitative data. Results: On availability and range of adolescents' sexual and reproductive health services, a total of 25
\end{abstract}


health facilities were surveyed. Forty four percent of the surveyed facilities did not have the adolescent sexual and reproductive health services (ASRHS). The Adolescents Sexual and Reproductive Health (ASRH) services offered differed greatly between facilities. On utilization of adolescents' sexual and reproductive health services in total, 204 adolescents from the community were involved in this study. A third of adolescents reported to have ever used ASRH. The adolescents perceived barriers for underutilization of the services were fear of being seen at the clinics (23.3\%), lack of money (18.3\%), lack of privacy \& confidentiality (14.2\%) and unfriendly health care providers. Three barriers were perceived by health care providers in the provision of ASRHS: integration of SRHS, lack of training in relation to adolescents SRHS and attitudes of health care providers towards young people. Conclusion: About half of the health facilities did not have the SRH-services to adolescent (44\%) and different ranges of services were not offered at the facilities as it was shown in the records. The results from this study show services were underutilized by adolescents. Training, attitudes of health care providers towards young people, \& cost influenced ASRHS provision and utilization. Strategies to increase training in ASRHS for health providers including communication skills and scaling ASRH services to all primary care facilities may help to improve availability and access of services to adolescents.

\section{Keywords}

Adolescent, Sexual Health, Reproductive Health, Utilization, Barriers to ASRH Services, Kinondoni Municipality and Tanzania

\section{Background}

World Health Organization (WHO) defines adolescents as young individuals aged between 10 - 19 years. Adolescence is a transition period between childhood and adulthood. Adolescents face varieties of health problems, such as unprotected sex, unwanted pregnancies, unsafe abortions, STIs including HIV infection leading to AIDS and finally death due to risk taking behavior and unavailability of wide range of sexual and reproductive health services for adolescents [1].

According to WHO, sexual health is a state of physical, emotional, mental and social well-being in relation to sexuality; it is not merely the absence of disease, dysfunction or infirmity while reproductive health is a state of being complete physical, mental and social wellbeing in matters related to the reproductive system including its functions and processes [1].

Worldwide about 1.2 billion people are adolescents. More than one in five of the World's populations are adolescents and four out of five live in developing countries [2]. In Sri Lanka, adolescents count for about $22 \%$ of the total population [2]. In Tanzania, 9.9 Million (23\%) of all Tanzanians population are adolescents [3]. While in India, adolescents account for one third (30\%) of the total 
population [3].

Adolescence period needs to be handled with great care and support. Physical and emotional changes are taking place which leads adolescents to become more questioning and wants to be independent on making decisions [4]. They also experience and take risks putting their health and future prospects at jeopardy. Since nearly $1 / 3$ of population in developing countries are adolescents, and nearly $45 \%$ are people $<15$ years, investing in adolescent health and overall wellbeing cannot be overemphasized. They are tomorrow's parents, teachers and leaders in different positions that is why there is a great need to reduce deaths and sexual \& reproductive problems, now and during their future lives [4].

The burden of SRH problems for adolescents is big worldwide. Globally, 11\% of all births occurred in adolescents [5]. According to Bearing and her colleagues on systematic review of studies on effectiveness of adolescents, sexual and reproductive services in developing countries showed that of the 19 million unsafe abortion occurring globally, adolescents contribute to $15 \%$ of them [5]. In SSA, $25 \%$ of unsafe abortions are in adolescents less than 19 years, while approximately $60 \%$ of all unsafe abortions are in 10 - 24 years old [6]. Studies have also shown adolescents have inadequate knowledge on pregnancy risks, prevention and low access to contraceptives [7]. Only 10\% - 16\% of adolescents use contraceptives in SSA. Sexually transmitted infections (STIs) are another common problem among the adolescents. According to WHO, there are about 340 new cases of curable STIs like syphilis, gonorrhea, chlamydia and trichomonas's occurring yearly; approximately $40 \%$ are among adolescents [8]. Different studies showed higher prevalence of Chlamydia and herpes simplex virus- 2 among adolescent girls in Tanzania and Uganda [8]. Further, $40 \%$ of new HIV infections in SSA are among adolescents and/or young people [9].

According to guidelines, sexual and reproductive health services for adolescents includes; access to information and counseling on sexual \& reproductive health issues, contraceptives including emergency contraceptives, STI screening and treatment, pregnancy, childbirth and postnatal care, post abortion management, counseling and testing for HIV, information and counseling on reproductive health, \& counseling and management of gender based violence [9]. Each country can add more or remove some services based on their needs [10]. These services should be provided in a friendly way, should be available, accessible and used by adolescents. Many countries including Tanzania have responded and developed adolescent sexual and reproductive health (ASRH) policies for the country [10].

WHO's focus is on making the existing health facilities more friendly to adolescents rather than setting up new service delivering unit for adolescents which separates them from adults [11]. WHO consider adolescents friendly services when every obstacle hindering adolescents to receive SRH are being cleared by ensuring that the main characteristics of adolescent friendly services are being met. And these main characteristics are; health services are accessible (adoles- 
cents are able to obtain the available health services), acceptable (when they are willing to obtain the available health services), equitable (when all adolescents are able to obtain the available health services, appropriate (when they are able to obtain the services of their choice) and effectiveness (when the services of their choice are been provided in the right way) [11]. Other characteristics of adolescents friendly services are when the attitudes of health care providers are non-judgemental and are consistent when dealing with adolescents and when the community knows where do adolescents get the services and being supportive to them [12]. For adolescents they consider friendly services if they are treated with respect and adhering to confidentiality [13].

In Tanzania, adolescents have substantial burden of SRH problems. It is estimated that 6 percent of young female and 7\% of male adolescents suffer from STIs annually which can lead to infertility [14]. A systematic review done by Williamson and others on utilization of services has showed low utilization of modern contraceptives by female adolescents in Tanzanian [15]. Adolescent pregnancy rates are high, as Tanzania Demographic and Health Survey showed that $52 \%$ of young women under the age of 19 are pregnant or had given birth [16]. Up to $30 \%$ of maternal deaths in adolescents in some districts are due to unsafe abortion. Testing for HIV is still a challenge to adolescents as one in four adolescent women had been tested while one in five male had ever tested for HIV [16].

Comprehensive knowledge on HIV and STIs is low. In the recent TDHS of 2010 , only $59.7 \%$ of adolescent's boys and girls had comprehensive knowledge on prevention of HIV [17].

Adolescent's sexual and reproductive health is being addressed in several Tanzanian policies like National Health Policy of 2007, Health Sector Strategies Plan III and in others [18]. Tanzania is one of the signatory to various international and regional conventions that promote adolescents sexual and reproductive health [18]. According to the Tanzania adolescent reproductive health strategy of 2011-2015 developed by the MOHSW the present range of adolescents sexual and reproductive services to be delivered in health facilities includes; information and counseling on reproductive health, sexuality and safe sex, testing services [19], management of STIs, VCT+ and PMTCT+, focused ante-natal care, care during child birth, postnatal care, post abortion care, contraception including emergency contraception, condom promotion and provision and referrals [19].

Despite of many policies being in place which support adolescents to access SRHS, Tanzanian adolescents still experience SRH problems as shown by some indicators of knowledge, users and access to care. Limited information exists on actual availability and range of ASRHS provided by health facilities in Tanzania. Further there is limited published work on utilization patterns of ASRHS by sexually active adolescents in the country despite having ASRHS in the country [20]. This study aims to determine the availability, range and utilization of sex- 
ual and reproductive health services for adolescents at Kinondoni Municipality, Dar es Salaam, Tanzania.

\section{Methods}

\subsection{Study Design and Area}

The design was a cross sectional descriptive study. The study was conducted at Kinondoni Municipality, one of the fifth districts of Dar es Salaam region.

\subsection{Selection Criteria of the Study Participants}

In clinical areas selection criteria were based on health care providers offering Sexual and Reproductive Health (SRH) servicesfrom the sampled healthcare facilities both government and private [nurses and clinicians in-charges of reproductive \& child health clinics ( $\mathrm{RCHc})]$.

Also in a community, the selection criteria were based on the sampling of adolescents aged $15-19$ years.

\subsection{Sampling Technique}

Multi stage random sampling was used in selecting the adolescents for the study.

First stage involved a random selection of one out of four divisions in the municipality and Kawe division was selected. The second stage involved a random selection of one ward (Mikocheni ward) out of thirty four wards within the Kawe division. In total two streets (Mikocheni " $\mathrm{A}$ " and Darajani) out of six were selected for study from the selected ward. Within the selected streets, each house with an adolescent aged 15 - 19 years was approached with the help of street leader and any adolescent meeting the inclusion criteria was invited to participate.

\subsection{Study Variables}

In the study, there were independent and dependent variables. The independent variable was age, sex, marital status. Level of education, cadres, years of practice,, religion, previous training of health care providers on provisions of sexual and reproductive health services by adolescents and previous training of in charges on provisions of sexual and reproductive health services for adolescentswhile the dependent variables constituteavailability of ASRH services at the facilities and types of ASRH services at the facilities, proportion and types of SRHS utilized by adolescents.

\subsection{Statistical Data Analysis}

\subsubsection{Quantitative Analysis}

Data analysis employed Statistical Package for Social Sciences (SPSS) version 16.0 for Windows (SPSS, Chicago IL, USA). The descriptive statistics were calculated. Mean and standard deviation were used to summarize continuous variables, whereas categorical variables were summarized by proportions and frequency tables. 


\subsubsection{Qualitative Analysis}

Content analysis was used following the following steps:

Step 1: Data were transcribed, where by a written version of an interview was created and data were organized into easily retrievable sections. But three of the health care providers were not willing to be recorded.

Step 2: Familiarization of information: the recorded information using digital audio recorder were listened several times by using a computer and head phone, materials was re-read several times, memos and summaries were made before the formal analysis began.

Step 3: Important points were highlighted with different highlighters.

Step 4: Information was categorized and coded with highlighters of different colors: After familiarization with the material and highlighting important quotes, preliminary coding was done whereby certain ideas crop up in the transcript were labeled.

Step 5: Patterns and connections between \&within categories were identified. Step 6: Interpretation of findings was done.

\section{Results}

\subsection{Availability of Adolescents' Sexual and Reproductive Health Services}

In total 25 health facilities were surveyed to see whether the sexual and reproductive health services for adolescents were available instead of 26 because one of the government health centre was promoted to hospital level.

About half of the health facilities surveyed had ASRH services 14 (56\%). The services were available in all the surveyed health facilities owned by the government. Table 1 shows the availability of adolescent sexual and reproductive health services by level and facility ownership status.

\subsection{Type of ASRH Offered as Reported by Health Care Providers}

Fourteen different SRH services were offered to adolescents, with family planning being offered in all the 14 health facilities followed by pregnancy test (93\%) and STI testing and management (93\%). The least offered SRH services were; education on sexuality and safe sex and post abortion care (57.1\%). None of the facilities offered services or counseling on sexual abuse or gender based violence (Figure 1).

\subsection{Comparison of Records and Reports of Different Types of Adolescents Sexual and Reproductive Health Services Offered by the 14 Health Facilities}

Information on number of adolescents who have received SRH care in the past 3 months prior to the study was obtained from records/registers at the 14 health facilities. There was big discrepancy between the reports of health providers on types of ASRH provided with facility records for most of the services, with exception of HIV-voluntary counseling and testing and antenatal care services. 
Table 1. Availability of adolescents' sexual and reproductive health services (ASRHS) by level of health facility $(\mathrm{N}=25)$.

\begin{tabular}{cccc}
\hline Level of facility & $\begin{array}{c}\text { Available Government } \\
\text { health facility } \mathbf{n} / \mathbf{N}\end{array}$ & $\begin{array}{c}\text { Available Private } \\
\text { health facility n/N }\end{array}$ & Total n/N (\%) \\
\hline Hospital & $1 / 1$ & $4 / 7$ & $5 / 8(62.5 \%)$ \\
Health center & $1 / 1$ & $1 / 2$ & $2 / 3(66.7 \%)$ \\
Dispensary & $4 / 4$ & $3 / 10$ & $7 / 14(50.0 \%)$ \\
Total & $6 / 6$ & $8 / 19$ & $14 / 25(56.0 \%)$ \\
\hline
\end{tabular}

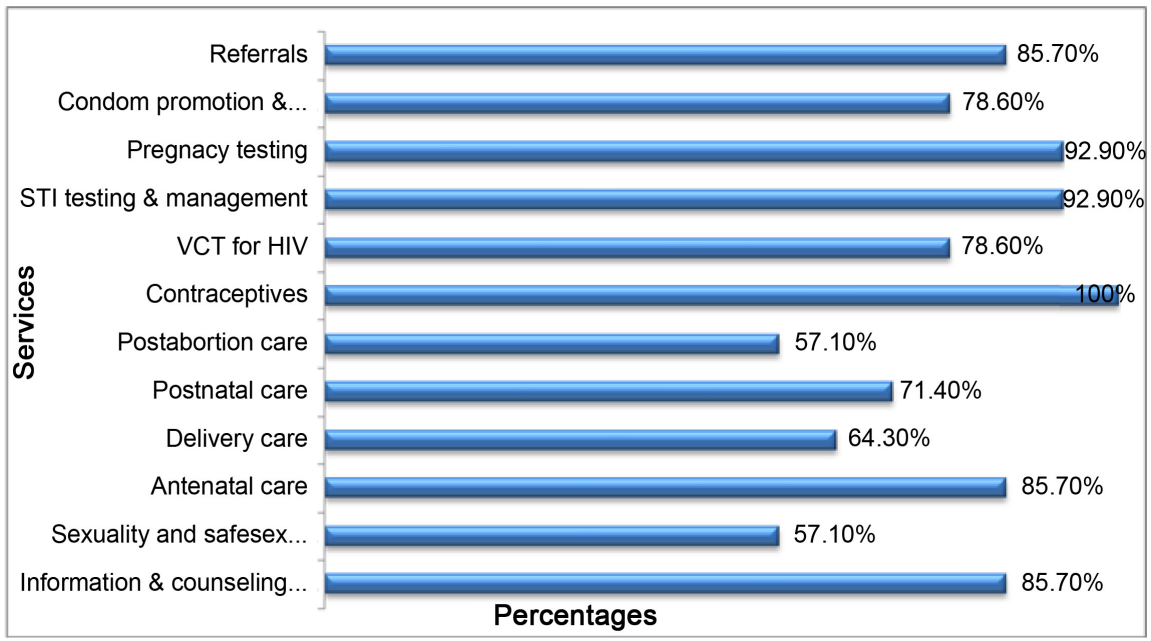

Figure 1. The range of sexual and reproductive health services offered to adolescents.

Three health facilities did not have any records of the services offered for adolescents (Table 2).

\subsection{Social Demographic Characteristics of Adolescents Who Utilization of SRHS}

In total, 204 adolescents from the community were involved in this study. Their mean age was 17.1 years (SD 1.4 years). Nearly 3 out of 5 participants were females and 56\% were still studying. Table 3 shows other social-demographic characteristics of the participating adolescents.

\subsection{Utilization of Sexual and Reproductive Health Services by Adolescent}

Only a third of adolescents (31\%) had used any sexual and reproductive health services, Adolescents who were sexually active utilized the services more than those who were sexually inactive, but in general, the majority of the adolescents had not utilized the services. Among the services being more utilized is information and counseling on reproductive \& sexual health services (32\%) and HIV-voluntary counseling and testing services (29\%). Services for contraceptives and for emergency contraception were utilized by $16 \%$ and $13 \%$ of sexually active adolescents respectively (Table 4). 
Table 2. Comparison of records and reports of different types of adolescents sexual and reproductive health services offered by the 14 health facilities.

\begin{tabular}{ccc}
\hline Services & $\begin{array}{c}\text { Recorded in the } \\
\text { past 3 months }\end{array}$ & $\begin{array}{c}\text { Reported available } \\
\text { in HF }\end{array}$ \\
\hline Information \& counseling on SRH & $3 / 11$ & $12 / 14$ \\
Education on sexuality and safe sex & $0 / 11$ & $8 / 14$ \\
Focus antenatal care & $10 / 11$ & $12 / 14$ \\
Delivery care & $1 / 11$ & $9 / 14$ \\
Post-natal care & $1 / 11$ & $10 / 14$ \\
Post abortion care & $2 / 11$ & $8 / 14$ \\
Contraceptives & $8 / 11$ & $14 / 14$ \\
VCT for HIV & $10 / 11$ & $11 / 14$ \\
STI testing and management & $4 / 11$ & $13 / 14$ \\
Pregnancy test & $0 / 11$ & $13 / 14$ \\
HIV management and treatment & $1 / 11$ & $11 / 14$ \\
Condom promotion and provision & $3 / 11$ & $11 / 14$ \\
Referrals & $0 / 11$ & $12 / 14$ \\
\hline
\end{tabular}

*: Three (3) health facilities did not keep any records for the provided services.

Table 3. Socio-demographic characteristics of adolescents who utilized SRHS (N = 204).

\begin{tabular}{|c|c|}
\hline Variables & $\mathrm{N}(\%)$ \\
\hline \multicolumn{2}{|l|}{ Residence: } \\
\hline Mikocheni "A" & $153(75.0)$ \\
\hline Darajani & $51(25.0)$ \\
\hline \multicolumn{2}{|l|}{ Sex. } \\
\hline Male & $93(45.6)$ \\
\hline Female & $111(54.6)$ \\
\hline \multicolumn{2}{|l|}{ Age (years): } \\
\hline 15 & $37(18.1)$ \\
\hline 16 & $30(14.7)$ \\
\hline 17 & 42 20.6) \\
\hline 18 & $50(24.5)$ \\
\hline 19 & $45(22.1)$ \\
\hline Mean $\pm S D$, years & $17.18 \pm 1.41$ \\
\hline Current studying. & $114(55.9)$ \\
\hline Std 7 & $1(0.9)$ \\
\hline O-level (Form 1 - 4) & $98(85.9)$ \\
\hline A-level (Form 5 and 6) & $4(3.5)$ \\
\hline College & $11(9.6)$ \\
\hline Currently not studying & $90(44.1)$ \\
\hline Those completed STD 7 & $70(34.3)$ \\
\hline Those completed form 4 & $20(9.8)$ \\
\hline
\end{tabular}


Table 4. Utilization of different sexual and reproductive health services by adolescents.

\begin{tabular}{cccc}
\hline $\begin{array}{c}\text { Services utilized } \\
\text { by adolescents }\end{array}$ & $\begin{array}{c}\text { Sexually-active } \\
(\mathbf{N}=124) \\
\mathbf{N}(\%)\end{array}$ & $\begin{array}{c}\text { Sexually-inactive } \\
(\mathbf{N}=80) \\
\mathbf{N}(\%)\end{array}$ & $\begin{array}{c}\text { Total }(\mathbf{N}=204) \\
\text { Utilized services } \\
\mathbf{N}(\%)\end{array}$ \\
\hline $\begin{array}{c}\text { Information and } \\
\text { counseling on SRH }\end{array}$ & $43(34.7)$ & $22(27.5)$ & $65(31.9)$ \\
$\begin{array}{c}\text { Counselling and } \\
\text { testing for HIV }\end{array}$ & $41(33.0)$ & $18(22.5)$ & $59(28.9)$ \\
$\begin{array}{c}\text { Counselling on } \\
\text { STI prevention }\end{array}$ & $39(31.5)$ & $9(11.3)$ & $48(23.5)$ \\
Testing and treatment of STI & $26(21.0)$ & $0(0)$ & $26(12.7)$ \\
Contraceptives & $20(16.1)$ & $0(0)$ & $20(9.8)$ \\
Pregnancy test & $6(4.8)$ & $0(0)$ & $6(2.9)$ \\
Focus antenatal care & $9(7.3)$ & $0(0)$ & $9(4.4)$ \\
Postnatal care & $9(7.3)$ & $0(0)$ & $9(4.4)$ \\
Post abortion care & $5(4.0)$ & $0(0)$ & $5(2.5)$ \\
Emergency contraceptives & $16(12.9)$ & $0(0)$ & $16(7.8)$ \\
\hline
\end{tabular}

\subsection{Barriers for Utilization of Sexual and Reproductive Health Services as Perceived by Adolescents.}

Fifty nine percent of adolescents $(n=120)$ perceived there are barriers on utilization of sexual and reproductive health services by the adolescents. Being shy and fear of being seen at the clinics 28 (23.3\%), lack of money $22(18.3 \%)$ and lack of privacy and confidentiality 17 (14.2\%) were the common perceived barriers by the adolescents. Table 5 shows other barriers on utilization of sexual and reproductive health services as perceived by adolescents.

\subsection{Barriers on Provision of ASRHS as Perceived by Health Care Providers}

In depth interviews were conducted with eleven health care providers instead of 14 health care providers with available of SRHS as saturation point was determined to get their views on challenges of provision of SRH to adolescents. The age of the participants ranged from 33 to 65 years old and the majority were female (8). Three key themes emerged when interviews with health care providers were analyzed; integration of SRHS where adolescents and adults are receiving care at the same place, Inadequate or lack of training in relation to adolescents SRHS and attitudes of health care providers towards young people. Other demographic characteristics of respondents are summarized in (Table 6, HCP2, HCP4, HCP6, HCP7, HCP8 \& HCP10).

\subsection{Integration of SRHS among Adolescents and Adults}

The main barrier on the provision of ASRHS as perceived by health care providers was integrating sexual and reproductive health services for adolescents and 
Table 5. Barriers perceived by adolescents on utilization of SRH-Services $(\mathrm{N}=120)$.

\begin{tabular}{ccc}
\hline Barriers & Frequency & Percentage \\
\hline Religion & 3 & $2.5 \%$ \\
Unfriendly health care providers & 12 & $10.0 \%$ \\
Fear and shy & 28 & $23.3 \%$ \\
Lack of money & 22 & $18.3 \%$ \\
Lack of health education & 12 & $10.0 \%$ \\
Young age & 11 & $9.2 \%$ \\
Lack of privacy and confidentiality & 17 & $14.2 \%$ \\
Lack of time & 9 & $7.5 \%$ \\
Shortage of health care providers & 2 & $1.7 \%$ \\
Drugs side effects & 4 & $3.3 \%$ \\
\hline
\end{tabular}

Table 6. Characteristics of respondents who participated in in-depth interviews $(\mathrm{N}=11)$.

\begin{tabular}{cccccc}
\hline Participant & Age & Sex & Education level & Cadre & Marital status \\
\hline HCP1 & 59 & F & Form four & Nurse Midwife & Widow \\
HCP2 & 49 & F & Form four & Enrolled Nurse & Married \\
HCP3 & 65 & F & Middle school & Nurse officer & Married \\
HCP4 & 50 & F & Form four & Nurse assistant & Married \\
HCP5 & 49 & F & Form four & Assistant Medical & Married \\
HCP6 & 50 & F & Form two & Public Health Nurse & Married \\
HCP7 & 46 & F & Form four & Nurse assistant & Married \\
HCP8 & 62 & M & Form six & Medical Doctor & Married \\
HCP9 & 38 & M & Form six & Medical Doctor & Married \\
HCP10 & 44 & F & Form four & Clinical officer & Married \\
HCP11 & 33 & M & Form six & Clinical officer & Married \\
\hline
\end{tabular}

Note: “HCP” stands for Health Care Providers.

adults. All eleven participants agreed on this without any hesitation. They are uncomfortable to mix the SRH services among adolescents and adults.

"When you integrate services you will have unusual mixer, as you find adults have clear purpose and know what they are looking for when they come to health facilities to seek for sexual and reproductive health services and it is vice versa to adolescents. They don't want to mix or to be seen with adults and they will come sneaking as thieves when there are few people. They deserve special area for service so they can be free to come at facilities and to share among themselves." ( $H C P 8)$.

Another health care provider added:

"When the services are integrated adolescents become speech less, to be honest you find an adolescent is suffering from STI because of fear he/she can't express free in front of adults and hel she can corner you and say I am suffering from headache. Sometimes they hide somewhere until adults are served as they 
fear to meet with someone familiar with... I think we have to set aside a special area for adolescents within the setting as we have enough space and we want to save both adults and adolescents but when you integrate the services you are not helping adolescents as they are very concealed' (HCP2).

\subsection{Inadequate or Lack of Training in Adolescents SRHS}

Lack of special training in relation to adolescents SRHS was the second barrier perceived by health care providers towards provision of the services. Only two health care providers out of 11 working in government health facilities have attended special training in provision of ASRH-services.

"I don't have enough skills to provide SRHS to adolescents as I have not attended any special training on $S R H S$ for adolescent' $s, \ldots$ I feel uneasily in providing sexual and reproductive health services to adolescents as I lack the skills and knowledge regarding the services. Communication in their language is difficult, maybe I will be more comfortable to serve adolescents if I will get special training on sexual and reproductive health services for adolescents" HCP6.

\subsection{Attitudes of Health Care Providers towards Young People}

Five health care providers perceived adolescents age as a barrier towards provision of sexual and reproductive health services to adolescents. They feel uncomfortable to provide the services to adolescents because of their age, saying some who seek the services are very young for the services or very young to be sexually active.

"I feel unhappy to provide the SRHS because other times children who are very young (11 years old) they come to you to seek for sexual and reproductive health services for example contraceptives or condoms. There is no way to say no, I have to listen and assist them, although I got hurt inside my heart" (HCP10).

Another health care provider added:

"I don't feel good to provide SRHS to adolescents. They are too young to be practicing sex, they should wait until they grow up, and that time will be appropriate time for them to utilize the services. What are we teaching if we give them services which are similar to adults? Are we giving them permission to be sexually active? I feel uncomfortable to give these condoms because some are very young" ( HCP4).

Another health care provider added:

“... For sure I am not comfortable because an adolescent of 16 years old when becomes pregnant unfortunately it does not pleases me for her to come for the service when she is having that particular age, I would love at-least to attend someone who is aged 24 and above" (HCP7).

\section{Discussion}

This study provides an overview of the sexual and reproductive health services to 
adolescents if they are available to what extent in our health facilities, the utilization patterns by adolescents and the barriers perceived by the health care providers towards the process of providing the services to adolescents.

The findings shows about half of the facilities had the ASRH services. More than ten ASRH services were reported to be provided in facilities providing ASRH, but records showed a contrasting picture. Only a third of adolescents have ever used ASRH services at facilities, with cost, being shy and privacy reported to be barriers for accessing care. On the other hand health providers perceived integration of SRHS, lack of training in relation to adolescents SRHS and personal attitudes towards young people as barriers to service provision.

The finding indicates about half (56\%) of the health surveyed facilities had the SRHS for adolescents available. The services were available in all of the government surveyed health facilities and only in 4 out of 10 private or FBO facilities. Similar to the study done in Port Vila Vanuatu, SRHS was available in $50 \%$ of the surveyed facilities and most being government owned health facilities [21]. However, these findings differ from the study done in Soweto South Africa. SRHS was available in all the three assessed health facilities [21]. This might be due to strong government policies in South Africa. In Kinondoni private or FBO facilities comprise $80 \%$ of the facilities, yet they are the ones most lacking ASRH services. This creates a significant barrier for availability and access of ASRH services for adolescents in the district. Adolescents will also be forced to use high cost for transport in seeking care as the services are not near to their residency affecting utilization of the services by adolescents. There is a need for the government and other stakeholders in SRH to make sure ASRH services are offered in all the health facilities of the district, especially private owned facilities.

The health providers reported nearly 14 different types of SRHS provided for adolescents at health facilities. But these services were not offered by all the facilities. Some SRH services were reported to be universal available like contraceptives, pregnancy testing and STI testing \& management while others like education on sexuality \& safe sex and post abortion care being the least. The findings are similar to the study done in Port Vila, where only family planning and condom provision were ASRH services offered by all the 8 surveyed facilities, with STI prevention and treatment, HIV counseling and testing, counseling on pregnancy prevention and prevention of sexual abuse was only available in $12 \%$ of the health facilities [22]. In Swaziland while antenatal care was offered by more than $60 \%$ of health facilities, contraceptives and HIV counseling and testing for adolescents were offered by $20 \%$ of the facilities [23]. The lack full range of ASRH by the facilities limits choice and ultimately affects utilization by the adolescents.

The study results showed big discrepancy between the reports of health providers on types of ASRH services provided with facility records on what was actually offered for most of the services in the 14 health facilities having ASRH services. For example while $93 \%$ of providers reported their facilities to offer STI care for adolescents, the records showed only $36 \%$ provided STI care for adoles- 
cents. Likewise while $92 \%$ and $86 \%$ of facilities reported to offer pregnancy and SRH counseling respectively, none of these was corroborated with the registers. One explanation maybe that while the services are available at the facilities, they are inaccessible to adolescents either due to lack of knowledge or skills in offering care to adolescents by providers or negative attitudes of the providers as described in this study and by other researchers elsewhere [24].

Another explanation maybe that because most of the facilities in the district had integrated services where adolescents and adults were offered SRH services at same area, adolescents feel there is lack of privacy, hence they are shy or fear to present their SRH problems to providers [24]. In this setting, there is a need to look further at what causes the discrepancy, since it shows there is a missed opportunity when the facilities have the services and adolescents are not accessing or utilizing them.

The study findings indicate low utilization of the SRH services by adolescents in Kinondoni municipality. While $61 \%$ of the adolescents were sexually active, only a third of reported to have ever used ASRH services at the facilities. Further, among the sexually active adolescents, only one in ten have ever used contraceptives, two in ten have received STI counseling care and management and only three in ten have ever received HIV counseling and testing. Similarly report by the WHO and studies done by in Burkina Faso, Ghana, Malawi and Uganda showed low utilization of the SRHS adolescents [24]. Multiple factors may influence utilization of services by the adolescents. Adolescents had reported they are shy to seek ASRH or they fear to be seen by other community members seeking SRH at the facilities. Biddlecom et al., observed similar findings in Uganda and Burkina Faso. Negative community attitudes towards use of contraceptives or condoms for adolescents have been shown to influence utilization of services by making adolescents hide that they are sexually active or have problems [24]. Perception of lack of privacy \& confidentiality also affects utilization of services. In Vanuatu, adolescents reported that the services were not youth friendly and lack privacy because they were mixed with adults when services for SRH were provided, and they strongly recommended separate setting for adolescents and adults services [25]. Likewise, in Mtwara Tanzania though SRH were available at all the assessed facilities, the services were adult oriented and didn't consider adolescents, thus they did not use them [25]. In Nepal adolescent reported that lack of confidentiality among health care providers was among the barriers for adolescents not accessing the facilities for SRHS [25]. Underutilization of the services creates high burden of sexual and reproductive health problems to adolescents like unsafe abortion, STIs/HIV, and birth complications. Designing a separate space/area for adolescents within the facilities to offer ASRH should be tried by few facilities at the district as suggested by adolescents and providers, and if it will improve utilization of services, then the DHMT can scale it to the remaining health facilities.

Low knowledge, skills and lack of training of health providers in ASRH has 
been described as a barrier for service provision in other studies, as found this setting. Only $20 \%$ of health care providers had reported to have received training on ASRHS. Most providers reported they feel uncomfortable and lack confidence in offering SRH to adolescents because they don't have skills to communicate with them and lacked background knowledge or training. This finding is in line with other studies done in different places. A qualitative study done on Southern part of Tanzania found indicates low knowledge of health care providers on ASRHS [26]. While a study in Swaziland showed lack of training of health care providers in relation to sexual and reproductive health services to adolescents as of great concern, the study showed majority of health care providers reported they had never attended any special trainings on ASRHS [26]. In Ethiopia the study results showed lack of training of health care provider as a barrier towards provision of sexual and reproductive health services to adolescents [26]). Investment in both in-service and pre-service training of health providers in general SRH and in adolescent SRH is required in most African countries.

Attitude of health providers may also influence utilization of services in a positive or negative way. Some providers had conflict in providing contraceptives to the adolescents due to their personal beliefs or attitudes. In Ethiopia, Tilahum et al., showed that majority of health care providers had positive attitudes towards adolescents, only $30.7 \%$ displayed negative attitudes toward adolescents [26].In Swaziland it was found providers didn't like to provide post abortion care or contraceptive for adolescents, and some even refused training for PAC [27]. This is a significant barrier perceived by adolescents of and it may interfere with the government efforts to reduce problems related to underutilization of SRHS to adolescents. It is important to provide more trainings for health care providers as it can act as a catalyst towards attitude change and reinforce positive attitudes of health care providers by being friendlier to adolescents.

\section{Limitations of the Study}

This study examined on availability, range, utilization of SRHS by adolescents and the barriers perceived by the health care providers in providing SRHS to adolescents. Hence, the study was based on self-reported information, and reporting bias by health care providers on ASRHS provided at the facility might have occurred. I tried to minimize by having a checklist of records of different ASRHS offered to adolescents in the past 3 months. The study was done in one Municipality (Kinondoni Municipality), for that reason it is very difficult to generalize them across other areas of the country. Also, adolescents may under-report on if ever had sex (had multiple questions addressing the issue; assured confidentiality).

\section{Conclusion}

Conclusion originating from this study shows, about half of the facilities did not have the SRH-services to adolescent. Different ranges of services were not offered to the facilities as it was shown in the records of adolescents who had uti- 
lized the services for the past three months and three health facilities did not had any records for the provided services. Services were underutilized by adolescents and among the barriers perceived by adolescents which might be the reasons for underutilization were shyness and fear of being seen at the clinics, lack of money, lack of privacy \& confidentiality, and unfriendly health care providers. Three barriers perceived by health care providers in the provision of SRHS to adolescents are integration of SRHS, inadequate or lack of training in relation to adolescents SRHS and attitudes of health care providers towards young people.

\section{Declarations}

Ethical consideration.

Before conducting the study, the ethical clearance was obtained from KCMU-College Research and Ethical Review Committee. Permission to conduct the study was sought from the Municipal Director of Kinondoni Council, District Medical Officer and in-charges of the selected health facilities for facility related data collection. Permission to collect information from adolescents at the community was sought from the DED and ward executive leaders of Kinondoni Municipality.

Consent was obtained from all in-charges of RCHC and adolescents or their parents/guardians before the study begins. Only numbers were used and not names on the questionnaires to maintain confidentiality. Health providers were assured that the information they provide will be used to improve ASRH care and not for other reasons.

\section{Acknowledgements}

Authors acknowledge everyone who provided support in the preparation of this scholarly paper. First of all, they would like to give thanks to Almighty God who made this work successfully. Secondly, the Ministry of Health Community Development Gender Elderly and Children (MoHCDGEC) for the financial support provided. Thirdly, the Municipal Director of Kinondoni Council, District Medical Officer and in-charges of the selected health facilities for facility related data collection. Fourthly, they extend special appreciation to Pastors Rev. Dr Huruma Nkone and Pastor Joyce Nkone (VCCT - Dar es Salaam), Remigius Modest Mawenya, Glory \& Josh Remigius Mawenya, Neema K. Ngabeki and her family, the family of Professor Joseph Mlay and Professor Roggers A. Mwakigonja for their prayers and moral support received throughout. Lastly but not least, special thanks goes to our participants for their support and cooperation shown during data collection period.

\section{Consent to Publish}

Not applicable.

\section{Availability of Data and Materials}

The datasets used and analyzed during the current study are available from the 
corresponding author on reasonable request.

\section{Funding}

All operational costs were met by the authors themselves.

\section{Authors' Contributions}

BKM came up with the idea about the study, participated in study design, literature search, data analysis and drafted the manuscript. Thereafter, SEM \& AAM contributed to the study design, data analysis, which is manuscript writing and editing. In the end, all the authors read and approved the final manuscript.

\section{Conflicts of Interest}

The authors declare that they have no competing interests.

\section{References}

[1] Agampodi, S.B., Agampodi, T.C. and Ukd, P. (2008) Adolescent's Perception of Reproductive Health Care Services in Sri-Lanka. )aBMC Health Services Research, 8, 98. https://doi.org/10.1186/1472-6963-8-98

[2] Bassey, E.A., Abasiattai, A.M., Asuquo, E.E., Udoma, E.J. and Oyo-lta, A. (2005) Awareness, Attitude and Practice of Contraception among Secondary School Girls in Calabar, Nigeria. Nigerian Journal of Medicine, 14, 146-150. https://doi.org/10.4314/njm.v14i2.37171

[3] Bearing, L.H., Sieving, R.E., Ferguson, J. and Sharma, V. (2007) Global Perspective on the Sexual and Reproductive Health of Adolescents: Patterns, Prevention and Potential. The Lancet, 369, 1220-1231. https://doi.org/10.1016/S0140-6736(07)60367-5

[4] Biddlecom, A.E., Munthali, A., Singh, S. and Woog, V. (2007) Adolescents' Views of and Preferences for Sexual and Reproductive Health Services in Burkina Faso, Ghana, Malawi and Uganda. African Journal of Reproductive Health, 3, 99-110. https://doi.org/10.2307/25549734

[5] Finer, L.B. and Philibin, J.M. (2013) Sexual Initiation, Contraceptive Use and Pregnancy among Young Adolescents. American Academy of Pediatrics, 131, 886-891.

[6] Friedman, H.L. (1994) Reproductive Health in Adolescence. World Health Statistics Quarterly, 47, 31-35.

[7] Holt, K., Lince, N., Hargey, A., Struthers, H., Nkala, B., McIntyre, J., Gray, G., Mnyani, C. and Blanchard, K. (2012) Assessment of Service Availability and Health Care Workers' Opinions about Young Women's Sexual and Reproductive Health in Soweto, South Africa. African Journal of Reproductive Health, 16, 283-293.

[8] Kalo, J. (2006) Utilization of Adolescent Reproductive Health Services by Young People in Vanuatu. Supported by: Ministry of Health, United Nations Population Fund Secretariat of the Pacific Community.

[9] Grimes, D.A., Benson, J., Singh, S., Romero, M., Ganatra, B., Okonofua, F.E. and Shah, I.H. (2006) Unsafe Abortion: The Preventable Pandemic. The Lancet Sexual and Reproductive Health Series. https://doi.org/10.1016/S0140-6736(06)69481-6

[10] Martins, L.B.M., Paiva, L.C., Osis, M.J., de Sousa, M.H., Neto, A.M.P. and Tadini, V. (2006) Knowledge of Contraceptive Methods among Adolescent Students. Revista 
de Saúde Pública, 40, 57-64. https://doi.org/10.1590/S0034-89102006000100010

[11] Mbeba, R.T., Mkuye, M.S., Magembe, G.E., Yotham, W.L., Mellah, A.O. and Mkuwa, S.B. (2012) Barriers to Sexual Reproductive Health Services and Rights among Young People in Mtwara District, Tanzania: A Qualitative Study. Pan African Medical Journal, 13, 13.

[12] Ministry of Health and Social Welfare (2011) National Adolescent's Reproductive Health Strategy. Dar-es-salaam.

[13] Mngadi, P.T., Faxelid, E., Zwane, I.T., Hojer, B. and Ransjo-Arvidson, A.B. (2008) Health Provider's Perceptions of Adolescent Sexual and Reproductive Health Care in Swaziland. International Nursing Review, 55, 148-155. https://doi.org/10.1111/j.1466-7657.2007.00625.x

[14] Nath, A. and Garg, S. (2008) Adolescent Friendly Health Services in India: A Need of the Hour. Indian Journal of Medical Sciences, 62, 465-472. https://doi.org/10.4103/0019-5359.48461

[15] Regmi, P.R., Teijlingen, E.V., Simkhada, P. and Acharya, D.R. (2010) Barriers to Sexual Health Services for Young People in Nepal. Journal of Health, Population and Nutrition, 28, 619-627. https://doi.org/10.3329/jhpn.v28i6.6611

[16] Speizer, I.S., Magnani, R.J. and Colvin, C.E. (2003) The Effectiveness of Adolescent Reproductive Health Interventions in Developing Countries: A Review of the Evidence. Journal of Adolescent Health, 5, 324-348. https://doi.org/10.1016/S1054-139X(02)00535-9

[17] Tanzania Demographic and Health Survey (2005) Tanzania Demographic and Health Survey 2004-05. National Bureau of Statistics and ORC Macro, Dar es Salaam.

[18] TDHS (2010) Tanzania Demographic and Health Survey 2010. National Bureau of Statistics and ORC Macro, Dar es Salaam.

[19] THMIS (2008) Tanzania HIV/AIDS and Malaria Indictor Survey (THMIS) 2007/08. National Bureau of Statistics. https://dhsprogram.com/pubs/pdf/AIS6/AIS6_05_14_09.pdf

[20] Tilahun, M., Mengistie, B., Egata, G. and Reda, A.A. (2012) Health Workers' Attitudes toward Sexual and Reproductive Health Services for Unmarried Adolescents in Ethiopia. Reproductive Health, 9, 19. https://doi.org/10.1186/1742-4755-9-19

[21] United Republic of Tanzania's Ministry of Health and Social Welfare (2005) Standards for Adolescent Friendly Reproductive Health Services. Ministry of Health and Social Science.

[22] United Republic of Tanzania (2011) Ministry of Health and Social Welfare National Adolescent Health and Development Strategy, 2011. Ministry of Health and Social Science.

[23] UNAIDS (2012) Global Report: UNAIDS Report on the Global AIDS Epidemic 2012. United Nations Programme on HIV/AIDS, Geneva. http://www.unaids.org/en

[24] WHO (2002) Adolescent Friendly Health Services: An Agenda for Change.

[25] WHO (2002) Defining Sexual Health: Report of a Technical Consultation on Sexual Health. Geneva.

[26] WHO (2012) Making Health Services Adolescents Friendly: Developing National Quality Standards for Adolescent Friendly Health Services.

[27] Williamson, L.M., Parkes, A., Wight, D., Petticrew, M. and Hart, G.J. (2009) Limits 
to Modern Contraceptive Use among Young Women in Developing Countries: A Systematic Review of Qualitative Research. Reproductive Health, 6, 3.

https://doi.org/10.1186/1742-4755-6-3 


\section{Appendices}

Appendix I: Checklist, For the Availability and Range of ASRH Services Provided at the Health Facility

District: Kinondoni

Name of health facility:

Type of health Facility: $01=$ Dispensary [ ] $02=$ Health centre [ ] $03=$ Hospital [ ]

Ownership of the health facility: $01=$ government [ ] 02 = Private [ ]

Do you offer ASRHS? Yes/ No

\begin{tabular}{|c|c|c|c|c|c|}
\hline \multicolumn{6}{|c|}{ LIST OF ALL ASRHS AT THE CENTRE. } \\
\hline & $\begin{array}{c}\text { ASRH } \\
\text { Services }\end{array}$ & YES/NO & $\begin{array}{c}\text { DAYS OR } \\
\text { HOURS } \\
\text { WHEN } \\
\text { SERVICES } \\
\text { ARE } \\
\text { AVAILABLE }\end{array}$ & $\begin{array}{l}\text { NUMBER OF } \\
\text { ADOLESCENTS } \\
\text { SEEN IN THE } \\
\text { PAST 3MONTHS }\end{array}$ & COMMENTS \\
\hline 1 & $\begin{array}{l}\text { Information } \\
\text { and counseling } \\
\text { on RHS }\end{array}$ & & & & \\
\hline 4 & $\begin{array}{l}\text { Sexuality and } \\
\text { safe sex }\end{array}$ & & & & \\
\hline 5 & $\begin{array}{l}\text { Focused } \\
\text { ante-natal care }\end{array}$ & & & & \\
\hline 6 & $\begin{array}{l}\text { Care during } \\
\text { child birth }\end{array}$ & & & & \\
\hline 7 & Postnatal care & & & & \\
\hline 8 & $\begin{array}{l}\text { Post abortion } \\
\text { care }\end{array}$ & & & & \\
\hline 9 & $\begin{array}{l}\text { Contraception } \\
\text { including } \\
\text { emergency } \\
\text { contraception }\end{array}$ & & & & \\
\hline 10 & $\begin{array}{l}\text { Condom } \\
\text { promotion and } \\
\text { provision }\end{array}$ & & & & \\
\hline 11 & Referrals & & & & \\
\hline \multicolumn{6}{|c|}{ TESTING } \\
\hline 12 & VCT, STI, UPT & & & & \\
\hline \multicolumn{6}{|c|}{ MANAGEMENT } \\
\hline 13 & $\begin{array}{l}\text { STI \& VCT+ } \\
\text { PMTCT+ }\end{array}$ & & & & \\
\hline Oth & tests available, list & hem & & & \\
\hline
\end{tabular}

1) Do you have special site/room to offer ASRHS? Yes/No

2) Do you offer regular services for adolescents? Yes/No

3) How many numbers of trained health care providers in ASRHS--------- 


\section{Appendix II: Interview Guide for Health Service Providers}

Name of health facility:

Type of health Facility: $01=$ Dispensary [ ] $02=$ Health centre $[\quad] \quad 03=$ Hospital [ ]

Ownership of health facility: $01=$ government [ ] $02=$ Private [ ]

1) Sex

2) Age

3) Marital status

4) Religious

5) Level of education

6) Carder

7) For how long have you been working in this clinic?

\section{Knowledge}

8) What is your understanding of youth-friendly services?

9) Can you tell us what do you understand about ASRHS?

10) Have you attended any specific training in ASRH services?

11) Which type of training did you attend?

12) What is your understanding of integrated ASRH services?

\section{Attitudes}

13) How do you feel providing ASRH services?

14) Are you comfortable integrating $\mathrm{SRH}$ services for adolescents in this clinic?

\section{Practices}

15) In your opinion, do you feel that young people have needs for $\mathrm{RH}$ services?

16) How can we make or encourage adolescents to visit your clinic if they need to discuss SRH matters with you?

17) What do you do when adolescents come with complications which you cannot handle?

18) What challenges do you face when providing ASRHS?

- Space/rooms and Knowledge/skills of providers

- Number of providers and drugs/supplies/equipment

- Integration with other services and large volume/number of clients

ID NUMBER 

Appendix III: Questionnaire for Adolescents on Utilization of
SRHS [English Version]

\begin{tabular}{|c|c|c|c|c|}
\hline $\mathrm{SN}$ & QUESTIONS & ANSWERS & CODE & NO \\
\hline \multirow{2}{*}{1} & \multirow{2}{*}{ Sex } & 1) Male & 01 & \multirow{2}{*}{ [ ] } \\
\hline & & 2) Female & 02 & \\
\hline 2 & Age & [ ] & & \\
\hline \multirow[b]{3}{*}{3} & \multirow[b]{3}{*}{ Are you a studying? } & 1) Yes & 01 & \multirow[b]{3}{*}{ [ ] } \\
\hline & & 2) No & 02 & \\
\hline & & $\begin{array}{l}\text { If yes which class are you? ---------If no which } \\
\text { class have you ended --- and what are you } \\
\text { doing? }\end{array}$ & & \\
\hline \multirow{3}{*}{4} & \multirow{3}{*}{ Have you had sex? } & 1) Yes & 01 & \multirow{3}{*}{ [ ] } \\
\hline & & 2) No & 02 & \\
\hline & & If yes at what age you initiated sex? & & \\
\hline \multirow{2}{*}{5} & \multirow{2}{*}{$\begin{array}{l}\text { Have you heard about } \\
\text { ASRHS? }\end{array}$} & 1) Yes & 01 & \multirow{2}{*}{ [ ] } \\
\hline & & 2) No & 02 & \\
\hline \multirow{6}{*}{6} & \multirow{6}{*}{$\begin{array}{l}\text { Which of the } \\
\text { following ASRHS } \\
\text { ever utilized by you? }\end{array}$} & 1) Information and counseling on RHS & 01 & \multirow{6}{*}{ [ ] } \\
\hline & & 2) HIV counseling \& testing & 02 & \\
\hline & & 3) Testing \&Treated for STI symptoms & 03 & \\
\hline & & 4) Contraceptives & 04 & \\
\hline & & 5) None & 05 & \\
\hline & & 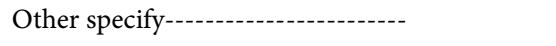 & & \\
\hline \multirow{6}{*}{7} & In addition to the above & 1) Antenatal care & 01 & \multirow{6}{*}{ [ ] } \\
\hline & question which among & 2) STI prevention & 02 & \\
\hline & the following ASRHS & 3) Postnatal care & 03 & \\
\hline & ever sought on & 4) Post abortion care & 04 & \\
\hline & counselling/utilized & 5) Emergency contraceptives & 05 & \\
\hline & the services? & 6) None & 06 & \\
\hline \multirow{7}{*}{8} & \multirow{7}{*}{$\begin{array}{l}\text { Where do you get the } \\
\text { ASRHS service from? }\end{array}$} & 1) Government health facility & 01 & \multirow{7}{*}[\quad]{} \\
\hline & & 2) Private health facility & 02 & \\
\hline & & 3) Pharmacy & 03 & \\
\hline & & 4) School & 04 & \\
\hline & & 5) Special groups/counselors & 05 & \\
\hline & & 6) No where & 06 & \\
\hline & & Other specify----------------- & & \\
\hline \multirow{3}{*}{9} & \multirow{3}{*}{$\begin{array}{l}\text { Are the health } \\
\text { facilities located } \\
\text { near a place where } \\
\text { adolescents live? }\end{array}$} & 1) Yes & 01 & \multirow{3}{*}{ [ ] } \\
\hline & & 2) No & 02 & \\
\hline & & 3) I don't know & 03 & \\
\hline \multirow{3}{*}{10} & \multirow{3}{*}{$\begin{array}{l}\text { Is the health facilities } \\
\text { open during hours that } \\
\text { are convenient } \\
\text { for adolescents? }\end{array}$} & 1) Yes & 01 & \\
\hline & & 2) No & 02 & [ ] \\
\hline & & 3) I don't know & 03 & \\
\hline & & 1) Yes & 01 & \\
\hline 11 & for free for adolescents? & 2) No & 02 & [ ] \\
\hline & & 3) I don't know & 03 & \\
\hline & Do health workers & & & \\
\hline & providers ensure & 1) Yes & 01 & \\
\hline 12 & privacy and & 2) No & 02 & [ ] \\
\hline & $\begin{array}{l}\text { confidentiality for } \\
\text { adolescents? }\end{array}$ & 3) I don't & 03 & \\
\hline
\end{tabular}




\section{Continued}

\begin{tabular}{|c|c|c|c|c|}
\hline 13 & $\begin{array}{l}\text { How long do you have } \\
\text { to wait at the health } \\
\text { facilities before you } \\
\text { see a health care } \\
\text { provider? }\end{array}$ & $\begin{array}{l}\text { 1) } 0 \text { - } 1 \text { hour } \\
\text { 2) } 1-2 \text { hours } \\
\text { 3) } 2-3 \text { hours } \\
\text { 4) } 3-4 \text { hours } \\
\text { 5) I have never attended } \\
\text { Other specify ------------- }\end{array}$ & $\begin{array}{l}01 \\
02 \\
03 \\
04 \\
05\end{array}$ & [ ] \\
\hline 14 & $\begin{array}{l}\text { Do you get the ASRH } \\
\text { services of your choice } \\
\text { when you go to health } \\
\text { facilities? }\end{array}$ & $\begin{array}{l}\text { 1) Yes } \\
\text { 2) No } \\
\text { 3) I have never attended } \\
\text { If no, do you think why? ----------- }\end{array}$ & $\begin{array}{l}01 \\
02 \\
03\end{array}$ & [ ] \\
\hline 15 & $\begin{array}{l}\text { Do you think the health } \\
\text { provider of SRHS for } \\
\text { adolescent explains the } \\
\text { information clearly? }\end{array}$ & $\begin{array}{l}\text { 1) Yes } \\
\text { 2) No } \\
\text { 3) I don't know }\end{array}$ & $\begin{array}{l}01 \\
02 \\
03\end{array}$ & [ ] \\
\hline 16 & $\begin{array}{l}\text { Do you think the health } \\
\text { care providers set aside } \\
\text { sufficient time for } \\
\text { client-provider } \\
\text { interaction? }\end{array}$ & $\begin{array}{l}\text { 1) Yes } \\
\text { 2) No } \\
\text { 3) I don't know }\end{array}$ & $\begin{array}{l}01 \\
02 \\
03\end{array}$ & [ ] \\
\hline 17 & $\begin{array}{l}\text { Do the health care } \\
\text { providers demonstrate } \\
\text { respect when } \\
\text { interacting with } \\
\text { adolescents? }\end{array}$ & $\begin{array}{l}\text { 1) Yes } \\
\text { 2) No } \\
\text { 3) I don't know }\end{array}$ & $\begin{array}{l}01 \\
02 \\
03\end{array}$ & [ ] \\
\hline 18 & $\begin{array}{l}\text { Are peer } \\
\text { educators/counselors } \\
\text { available in the health } \\
\text { facilities during the } \\
\text { provision of ASRHS? }\end{array}$ & $\begin{array}{l}\text { 1) Yes } \\
\text { 2) No } \\
\text { 3) I have never attended } \\
\text { If no what do you feel about that? }\end{array}$ & $\begin{array}{l}01 \\
02 \\
03\end{array}$ & [ ] \\
\hline 19 & $\begin{array}{l}\text { Are there any factors } \\
\text { which hinder } \\
\text { you to utilize } \\
\text { ASRH services? }\end{array}$ & $\begin{array}{l}\text { 1) Yes } \\
\text { 2) No } \\
\text { If Yes what are those factors? }\end{array}$ & $\begin{array}{l}01 \\
02\end{array}$ & [ ] \\
\hline 20 & $\begin{array}{l}\text { Is there anything you } \\
\text { think could be done to } \\
\text { improve services? }\end{array}$ & $\begin{array}{l}\text { 1) Yes } \\
\text { 2) No } \\
\text { 3) I don't know } \\
\text { If yes what do you think should be done? }\end{array}$ & $\begin{array}{l}01 \\
02 \\
03\end{array}$ & [ ] \\
\hline
\end{tabular}

